\title{
CONCEPTUAL AND PRACTICAL PROBLEMS OF EVALUATION OF INTERNATIONAL RYI POLICIES
}

\author{
KLAUS SCHUCH \\ DOI: 10.22163/fteval.2020.488
}

\section{INTRODUCTION AND SCOPE}

$\mathrm{T}$ his article discusses major conceptual and practical problems of evaluating internationally oriented R\&I strategies and policies of a number of European Member States. The article, however, is not based on an originally exercised evaluation study but systematises and summarises results from a so-called Mutual Learning Exercise, which has been implemented under the Horizon 2020 Policy Support Facility. The findings deal with the complexity of Ryl internationalisation strategies and their specific policies and support schemes, and in particular the difficulty in conceptually approaching them in evaluative ways due to various factors. These include shortcomings in the logic and design of the Ryl internationalisation strategies, the identified gap between the high-level internationalisation objectives and the specific policies as well as practical issues concerning data and indicators.

In section 2, we provide information about the Horizon 2020 Policy Support Facility and the Mutual Learning Exercise on National Strategies and Roadmaps for International Cooperation in R\&l, which constituted the operational and methodological framework as well as the empirical basis of the findings presented in this article.

In section 3, we discuss how some of the conceptual deficits of Rql internationalisation strategies impede evaluations that are more complex and in section 4 we focus on fundamental practical challenges of evaluating R\&I internationalisation policies.

Both in section 3 and section 4, we also aim to explain the background and reasoning for the two main recommendations regarding evaluative issues, which were elaborated during this Mutual Learning Exercise on National Strategies and Roadmaps for International Cooperation in R\&l.

\section{THE HORIZON 2020 POLICY SUPPORT FACILITY AND THE MUTUAL LEARNING EXERCISE ON INTERNATIONAL COOPERATION IN RGI}

The Horizon 2020 Policy Support Facility (PSF) is a specific instrument of the European Commission funded under Horizon 2020. It gives Member States and countries associated to Horizon 2020 practical support to design, implement and evaluate reforms that enhance the quality of their research and innovation investments, policies and systems.

The Policy Support Facility aims to provide best practice, independent high-level expertise and guidance at the request of Member States and countries associated to Horizon 2020 (i.e. Associated Countries) to support evidence-based policy making through a number of services: Peer Reviews, Mutual Learning Exercises and Specific Support to Countries. An evaluation of the PSF has shown that the instrument is of high quality, appreciated by the clients and effective to induce policy reflection, however, with one major weakness. This major weakness is the followup on the established recommendations and the lack of or difficult access to follow-up support to turn recommendations into practice (MeyerKrahmer et al., 2019). At operational level, the European Commission has been supported in the implementation of the PSF by a consortium consisting of Technopolis Belgium (lead), the Manchester Institute of Innovation Research and the Centre of Social Innovation (ZSI).

In contrast to the 'Peer Review scheme' and the 'Specific Support to Countries scheme' offered by the PSF, which usually target and support single countries, Mutual Learning Exercises (MLE) focus on specific R\&l challenges of interest to several Member States and Associated Countries. MLEs aim to identify good practices, lessons learned and success factors based on robust evidence. Exchange of experiences and policy learning constitute the scope of MLEs.

The MLE on 'National Strategies and Roadmaps for International Cooperation in Research and Innovation' (R\&I) (abbreviated by INCO MLE) has been implemented between March 2019 and February 2020. Its task was to organise an intense policy exchange about various national approaches towards international cooperation in R\&I. Particular attention was paid to sustained challenges of R\&I internationalisation and new 
or upcoming developments. The following countries participated in the INCO MLE: Austria, Belgium/Flanders, Denmark, Finland, France, Greece, Hungary, Ireland, Moldova, Norway, Portugal, Romania, Slovenia, Sweden and Turkey. It goes without saying that these countries differ a lot as regards their RgI internationalisation strategies and activities. Generalizations are therefore difficult.

Evaluation of international R\&I policies was just one among several other topics. This article highlights the main findings regarding the corresponding issues of monitoring and evaluation. Other important topics of the INCO MLE included, among other issues, diverse aspects of strategy development, consideration of SDGs in policy designs, multi-stakeholder funding activities, STI agreements and good cooperation principles. The reports of this MLE, which cover all these topics and more, can be accessed via the website of the Research and Innovation Observatory of DG $R \& I^{1}$. They provide a complete picture of the various aspects discussed during the MLE on 'National Strategies and Roadmaps for International Cooperation in Research and Innovation'.

Different methods were applied to gain country-related information and to organise the engagement and exchange of the participating countries. These included country visits (to France, Romania and Sweden), input provided by external experts in form of challenge papers, which were then elaborated into Thematic Reports, input presentations from various country delegates from ministries and agencies in charge for R\&। internationalisation, and several targeted discussion rounds. In addition, a considerable amount of input in terms of taking stock of the current practices of the MLE participants were gathered through three surveys that were carried out prior to the country visits (Schuch et al., 2020).

Survey 1 dealt with important aspects related to the design and development of national strategies for international Ryl cooperation. Survey 2 investigated the substance, structure and use of Science and Technology Agreements (STA), differentiating between successful and less successful approaches and examples. Survey 3 finally scrutinised the attitudes, practices and uptake of challenge-driven approaches, as well as existing and novel 'good principles' in international R\&l cooperation.

The findings from these surveys and the subsequent discussions and findings are systematised and summarised in three Thematic Reports (Schuch, 2019; Boekholt, 2019; Könnölä, 2019), which can be accessed from the PSF website?

\section{CONCEPTUAL CHALLENGES OF RGI INTERNATIONALISATION STRATEGIES AND POLICIES}

Although a considerable body of literature provides evidence on RYl internationalisation in general (Dachs 2017; Schuch, 2017; OECD, 2016; Deuten, 2015; Alkemade et al., 2015; Laurens et al., 2015;0ECD 2010;
Hall 2010; Shapira et al. 2009; Hatzichronoglou 2008; OECD 2008a; OECD 2008b; OECD 2008c; OECD 2005; UNCTAD 2005,), mostly focussing on internationalisation of multi-national enterprises, a much lower volume of literature is available on international comparisons of Rgl internationalisation policies (SFIC 2019; SFIC 2018; SFIC 2015; Schwaag-Serger and Remoe 2012; Schwaag-Serger and Wise 2010; TAFTIE 2009; Boekholt et al., 2009; CREST Working Group 2007).

Our findings have shown that most of the participants of the INCO MLE have developed R\&I internationalisation strategies, which are either single-standing documents or integrated parts in overall national strategies. Most RGI internationalisation strategies usually include both cooperation within and outside Europe with emerging and developing countries ${ }^{3}$. In many - but not all - cases, the knowledge triangle research-innovation-education is covered. Some countries focus explicitly on innovation, while others are more hesitant in this direction. In addition to goals deemed to strengthening the specific country's own position in terms of scientific excellence or global competitiveness, many countries also consider the mutual tackling of global challenges as an important task of research cooperation or define goals in the field of science diplomacy.

Figure 1: Importance of R\&l internationalisation within the national R\&l strategy (top) and within the national strategic policy discussions (bottom)
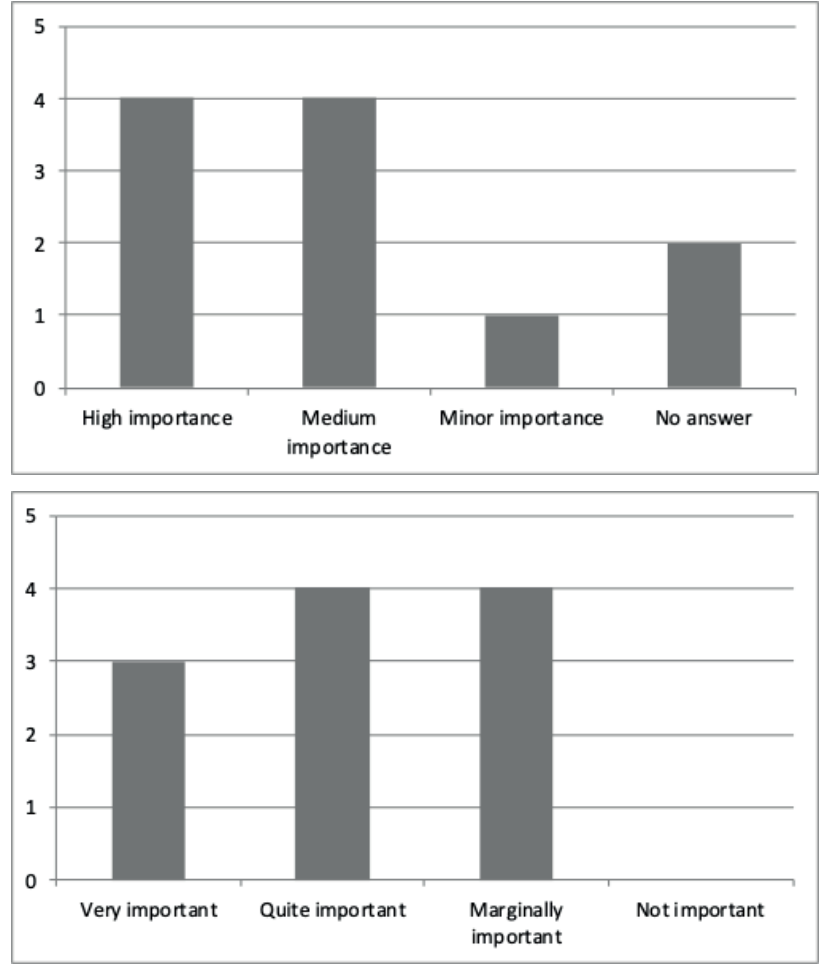

Source: First survey sent to MLE participants, n=11; Schuch et al. (2020).

1 https://rio.jrc.ec.europa.eu/policy-support-facility/mle-national-strategies-and-roadmaps-international-cooperation-research-and; accessed on 30 September 2020.

2 https://rio.jrc.ec.europa.eu/policy-support-facility/mle-national-strategies-and-roadmaps-international-cooperation-research-and; accessed on 3 October 2020.

3 For instance, the Austrian 'Beyond Europe'-R\&l internationalisation strategy is an exception, because it focuses only on non-EU countries 
Eight of eleven country delegates, who participated in a first survey launched under this MLE mentioned that the aspect of internationalisation within their overall national Rgl strategy is very important or at least of medium importance (see Figure 1, top hand side). The 'no answer' responses were given by MLE participants who did not have an overall national R\&I strategy. If asked, however, how important the aspect of internationalisation is within the strategic policy discourses in their countries, then the picture becomes more blurred (see Fig. 1, bottom hand side). This blurred picture might indicate that Ryl internationalisation is sometimes considered rather as an appendix or a 'nice to have' than integrally positioned within core elements of national Rql strategies.

The INCO MLE participants confirmed more or less the findings from literature (Boekholt et al., 2009; CREST, 2007) that most of the R\&I internationalisation strategies of EU Member States focus on the 'Excellence Objective', 'Market (or innovation) Objective', 'Global (or Grand) Challenges Objective' and 'Science Diplomacy Objective', but they added the 'Development of the ERA Objective' as further main objective (see Fig. 2). The latter is not at least caused by the inclusion of Associated Countries in the INCO MLE, for whom ERA integration is of particular importance.

According to Boekholt et al. (2009), the objectives can be differentiated by a narrow and a broader STI cooperation paradigm. In the narrow STI cooperation paradigm, the drivers for international research collaboration policies aim to improve the quality, scope and critical mass in science and research by linking national resources and knowledge with resources and knowledge in other countries. Here, the drivers originate from within the science community and are translated into science and research policy instruments. The 'Excellence Objective' represents the 'purest' narrow STI cooperation objective. In the broad STI cooperation paradigm other non-science policy objectives also interact with the 'intrinsic' science-oriented paradigm and STI cooperation becomes a means to reach other policy ends. According to Boekholt et al. (2009) these other policy ends relate to (i) improving national competitiveness, (ii) supporting less developed countries by developing STI capabilities, (iii) tackling global societal challenges and (iv) creating good and stable diplomatic relationships. ${ }^{4}$

During the INCO MLE discussions, it also became clear that the emphasis in current Ryl internationalisation policy is changing. While RYl internationalisation policy had almost only positive connotations in the past, it is now much more geared towards concrete outcomes and a growing sensitivity towards cooperation with certain countries. This is mainly caused by competitiveness concerns as well as concerns regarding ethical conduct of R\&l activities. The concern about competitiveness issues is amplified by the fact that innovation-related rationales are becoming more prominent in current R\&l internationalisation thinking. This is grounded in a more economic understanding and rationale of Science and Technology (S\&T) policy-making in general. It is, however, also propelled by the challenge-driven approach, which basically bridges research to innovation-related activities in different social spheres.

Although recognised as a strong driver of economic growth and structural change, innovation is perceived as disruptive to the field of

Figure 2: Ranking of RGl internationalisation objectives

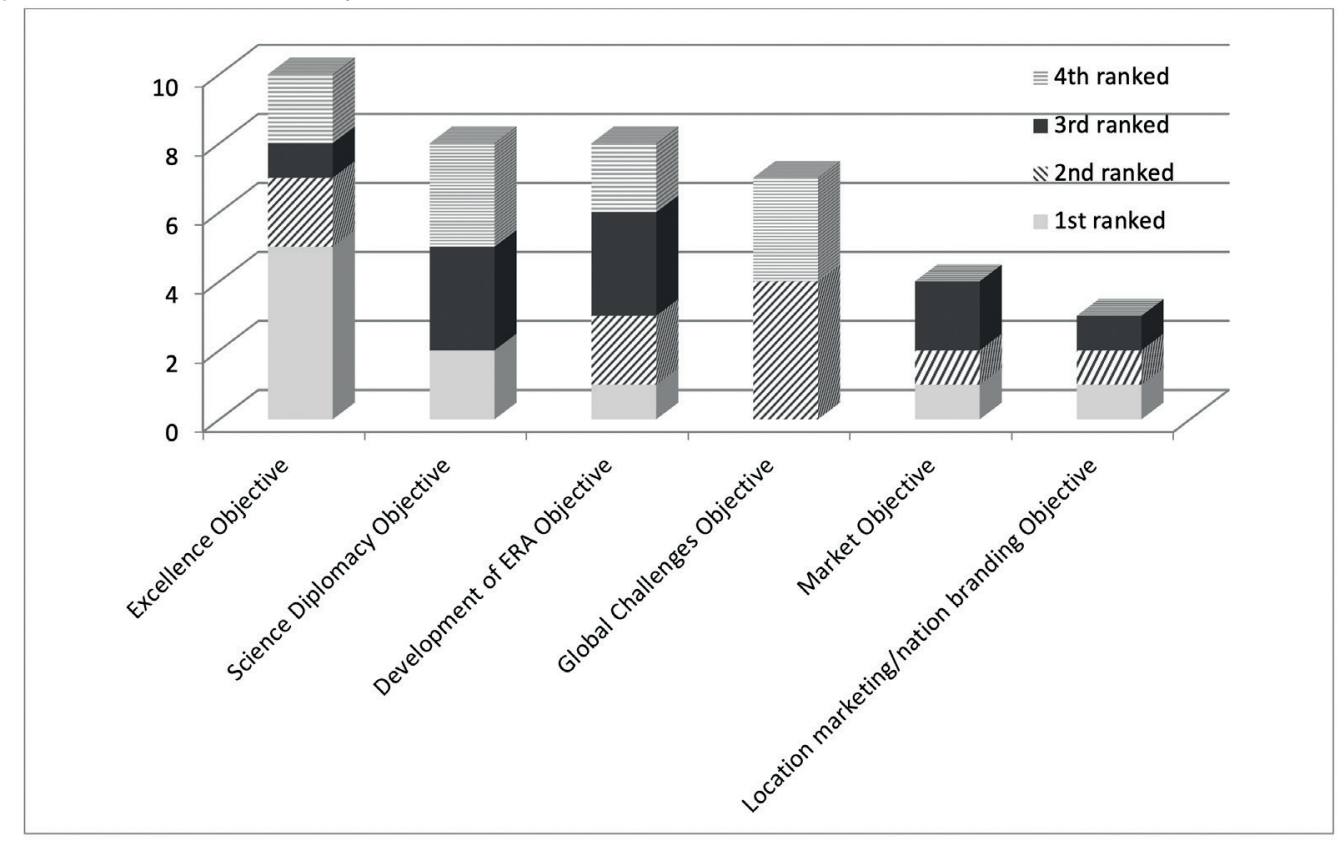

Source: First survey sent to MLE participants; own calculations; $n=11$; Schuch et al. (2020). 
international S\&T cooperation (Schuch, 2019), because it creates winners and losers. Traditional international S\&T policy strategies, however, typically aimed to support pre-competitive mutual benefit through cooperation in fundamental sciences. Accordingly, the specific interventions to foster international RGD cooperation were - and still to a large extent are - focusing mainly on areas of basic research and international mobility of researchers and students, with quite some conscious distance from immediate commercial interests. All INCO MLE participants agreed that it is a challenge to bring the different spheres of 'academic knowledge production' and 'business-driven innovation practices' together and to develop R\&l internationalisation approaches that combine these spheres (possibly including also public sector innovation, social innovation and common public good aspects). Two of the eleven participants responding to the first survey mentioned that 'innovation' and 'science' are 'worlds apart' in their internationalisation practices and four more countries confirmed that this is at least partly the case (Schuch et al., 2020).

The ongoing shift in rebalancing and valuing the at least partly competing R\&I internationalisation objectives and the perceived quest for adequate and meaningful implementation policies are challenging the existing Rql internationalisation strategies.

There was consensus among the INCO MLE participants, that international $R \& \mid$ cooperation should be designed as strategically as possible in order to achieve the best possible impact. The basic feature of a strategy is that it defines clear goals and provides orientation on how and which Ryl internationalisation policies are developed and implemented (i.e. a policy-mix oriented intervention logic). A clear intervention logic (e.g. based on a Theory of Change) would help to lay out the sequence of outcomes that are expected to occur as result of a set of interventions by applying clear policies. In other words, a logical deduction for an intervention pathway would, firstly, take the new and upcoming framework conditions for international R\&I cooperation into account. It would, secondly, start with high-level objectives and rationales about the expected changes that policy interventions should trigger or enforce. These would then be broken down into specific activities, measures and outputs that are supposed to drive the change. Such a logic seems desirable but is hardly available in practice. Moreover, to track the results of policy interventions, clear intervention logics would certainly facilitate the work of evaluators.

The first survey among the INCO MLE participants, however, showed that only a few of the responding countries fully apply a Theory of Change for their international R\&l cooperation strategy (Schuch, 2019). Only some Ryl internationalisation strategies list a series of policy interventions to the identified objectives. The Austrian 'Beyond Europe' strategy is a good example for this, without, however, making a clear logical connection or pathway between the overall objectives and the policy interventions (which are mostly either programmes, or instruments or other measures or initiatives) explicit. Such a logical deduction of an intervention pathway could be qualified as an explicit Theory of Change that asks about what will have changed or what changes will have occurred due to policy interventions. Thus, the ToC approach focuses much on the tangible (sequence of) outcomes/results of an intervention or a portfolio of interventions, and not just on the overall objectives. The quality of a ToC can be approximated by plausibility (i.e. the logic of the outcomes pathways), the feasibility (i.e. can the proposed interventions realistically achieve the expected long-term outcomes and impact) and testability (which refers broadly to the indicators). In a further step, an evaluation could track whether these expected outcomes could have been actually produced (or not). R\&I internationalisation strategies that are using intervention logics enable easier tracking of whether the expected outcomes have been actually achieved (or not) and can be better evaluated.

Fig 3: Availability of a Theory of Change for RqI Internationalisation Strategy

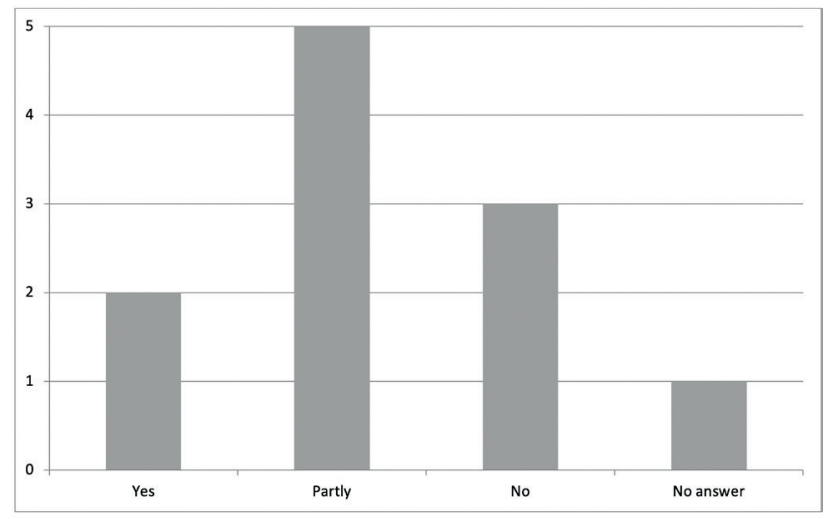

Source: Survey sent to MLE participants; $n=11$; Schuch et al. (2020).

As shown in Fig. 3, however, traceable Theories of Change or intervention logics were hardly formulated in Ryl internationalisation strategies, although many countries include some elements of it. Although RYI internationalisation strategies propose (rather broad) objectives, clear and logically integrated connections as to concrete outcomes, approaches, operational measures and proposed or available resources are often lacking (see for instance the Austrian Ryl internationalisation strategy 'Beyond Europe'). We repeatedly identified gaps between boldly formulated high-level objectives and specific interventions, which should be directly derived from them or responding to them. In reality, some of the practised internationalisation interventions, especially those that are not coupled with domestic R\&I programmes and instruments, seem rather under-critical and hardly able to make substantial contributions to the overall goals. Sometimes these are legitimised by science diplomacy considerations.

Not surprisingly, one main recommendation of the MLE was to include a logic-based approach in the process of developing future R\&l internationalisation strategies or roadmaps.

Box 1: Apply a clear intervention logic to substantiate international R\&। cooperation strategies

The recommendation is to take a clear intervention logic based approach in the process of developing R\&l internationalisation strategies or roadmaps. How to make use of a broad understanding of innovation and operationalise it for the purpose of an inclusive and effective international $R \& /$ cooperation should be scrutinised in particular.

Addressee: The national R\&l policy-making level responsible for establishing a strategy or roadmap for international R\&l cooperation and the designers of specific policies (e.g. Ryl cooperation programmes, instruments or initiatives). 


\section{PRACTICAL PROBLEMS OF MONITORING AND EVALUATING RGI INTERNATIONALISATION POLICIES}

As for any other public intervention, it is important to check the progress of the implementation of Ryl internationalisation and to identify and assess the results, which can be attributed to it. Of primary interest is to understand how and to what extent the internationalisation interventions, which should normally be derived from the existing internationalisation strategy or directly respond to it, contributed to the objectives stipulated by the strategy. As shown in the previous section, however, the gap between high-level objectives and the derivation and design of concrete support schemes is quite large and unclear, which impedes more efficacy and outcome-oriented evaluative approaches. Moreover, continuous collection of Ryl internationalisation data for monitoring purposes, especially beyond Europe, is very rare and evaluations in the field are just occasionally implemented (Boekholt, 2019; Schuch, 2019).

From a strategic point of view, Edler and Flanagan (2009) identified needs for evaluations of Ryl policies and corresponding indicators at four stages:

- Evaluations with corresponding indicators to describe and assess the status quo of the internationalisation of the R\&l system under investigation. This is in particular important before an Ryl internationalisation strategy or roadmap is developed and adopted.

- Indicators to set targets and to make choices. The definition of a desirable scale and scope of activities is a key challenge, because, per se, more internationalisation is not always necessarily better.

- Indicators to understand the international 'opportunity environment'. Good intelligence regarding potential international R\&I cooperation countries is vital.

- Evaluations with adequate indicators to verify if important initiatives, programmes and instruments work in the way as they were designed. Evaluations of individual programmes and instruments or portfolios of programmes and instruments scrutinise their relevance, effects (outputs and results) and - if possible - impacts.

In the following paragraphs some examples of Ryl internationalisation indicators are shown which are repeatedly mentioned and used in studies and assessments. Our research revealed that there is no shortage of input or output related indicators, but of outcome and impact related indicators and corresponding data. Extensive lists of indicators for example have been compiled by Brandenburg and Federkeil (2007) for measuring internationality and internationalisation of higher education institutions and by Schuch (2011) for measuring the internationalisation of science and research (see the examples provided in Box 2). Such internationalisation indicators can be grouped in different categories depending on the respective purpose. As follows, a possible distinction is made between $R$ gl internationalisation indicators at the level of:

- embedding of an R\&I internationalisation strategy in a broader domestic R\&l strategy

- at systems level

- at the level of research organisations

- at individual researchers level.

Box 2: Examples of RqI internationalisation indicators

\section{R\&I INTERNATIONALISATION INDICATORS}

Indicators related to embedding of the R\&I internationalisation strategy in broader domestic R\&l strategies Examples:

- How many of the national programmes/instruments/tools have an R\&l internationalisation component (or are fit and open for it in general) (mainstreaming)?

- How much budget is allocated for R\&I internationalisation in these domestic programmes/instruments/tools?

- What is the scope and size of targeted (uni-, bi- and multi-lateral) Ryl internationalisation measures?

- Extent of participation, volume and share in European or international R\&l schemes (JPIs, int. ERA-NETs, international research infrastructures etc.)

\section{Indicators at system's level}

Examples:

- Financial indicators (R\&D budget inflow/outflow; share of high-tech exports)

- International representation related indicators (R\&D offices abroad; staff in international R\&I organisations; participation in regulatory or standards setting)

- Scientometrics (publications and co-publications differentiated by themes, countries, regions; EPO and USTPO patents)

- Mobility patterns (share of foreign academic staff at public research organisations and universities; share of international students/graduates)

- Project related indicators (e.g. juste retour from FPs) 


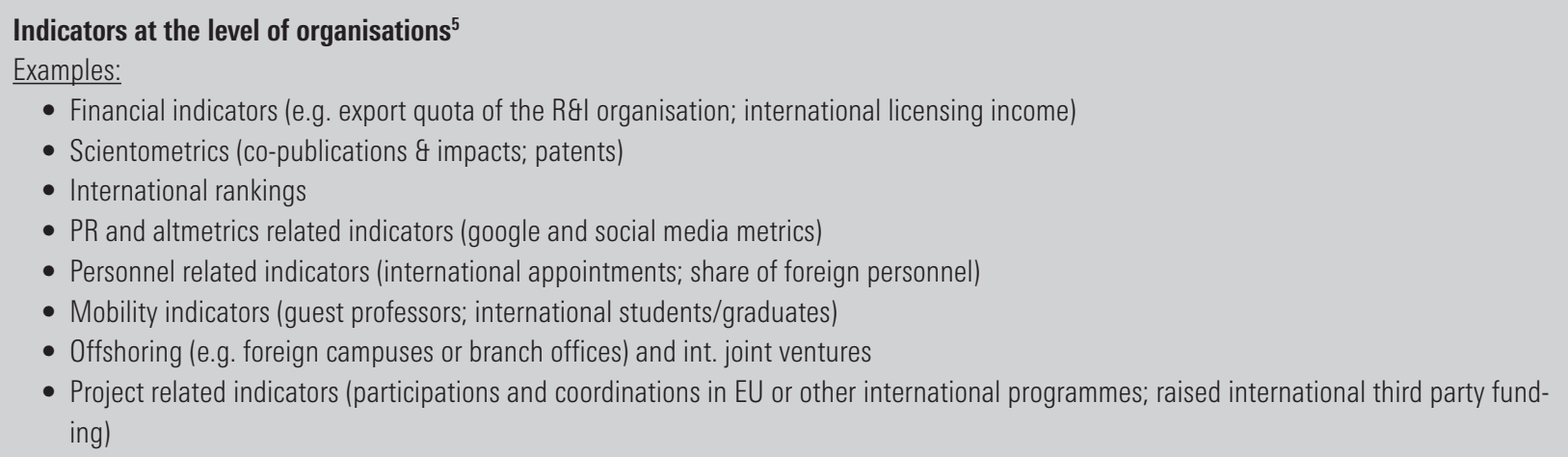

\section{Indicators at individual level}

Examples:

- Publication related indicators (quantity and quality)

- Patent related indicators

- Scientific and non-scientific speeches (conference participation)

- Participation in international bodies (e.g. advisory groups of the EC; editorial boards ...)

- Mobility related indicators (e.g. international research stays; international appointments)

- Degrees obtained abroad

- Number of supervised international students including cotutelle de thèse

- Project related indicators (e.g. participation in FPs; coordination of FP projects; international funding raised)

Embedding indicators and indicators at the systems level are the most relevant indicators for the assessment of the status quo of internationalisation of a specific country's or region's Ryl system (Schuch, 2019). While these indicators usually target a higher level of aggregation to describe and assess a certain situation or status quo, they hardly measure the impact or Ryl internationalisation in terms of, e.g. lasting networks, knowledge and innovation-related results and outcomes, dissemination of knowledge or contributions to environmental and societal challenges (Fikkers and Horvat, 2014; Gnamus, 2009).

Another problem is the adequacy (i.e. relevance, reliability and validity) of the indicators used. Indicators should be capable to capture and measure the basic properties and objectives of the R\&l internationalisation strategy and its underlying Theory of Change. There are no 'one-sizefits-all' indicators and no 'one-size-fits-all' methodological recipes. Different indicators are needed for different considerations and purposes. Thus, specific indicators need to be constructed, using metrics that are universal, precise, unambiguous and relevant. Unfortunately, the number of evaluations of international R\&l cooperation interventions is still so limited that, for the time being, a robust stock of knowledge about the adequacy of the indicators used is lacking.

Another problem is that R\&I internationalisation data are often uneven and have limited comparability. Thus, a good monitoring system, internationally co-ordinated and organised by the agencies responsible to support RyI internationalisation or based e.g. on the availability of well-maintained and comparable current research information systems (CRIS) is advantageous. For comparative bibliometric-based analysis, a certain dependency on commercial data providers can be ascertained. Since often monitoring data as well as secondary data on RqI internationalisation are not sufficient or available, case-based evaluative sur- veys are still common practice. They are costly and often only one-off activities. However, for assessing the progress of R\&l internationalisation they should be repeatedly implemented for monitoring purposes. Thus, several studies already recommended launching pilot surveys on European level or at least co-ordinated by a couple of European countries on variable geometry (Vullings et al., 2013). It is assumed that the use of jointly agreed indicators and methodologies to assess the impact of national and European R\&l internationalisation policies would increase comparability between countries and contribute to standardisation of indicators, methods and practices. Due to their 'beyond academic impact' orientation, challenge-driven international $R \& \mid$ cooperation activities could be taken as a starting point.

Attribution problems, e.g. the logical and de facto connection between inputs (e.g. resources assigned to certain interventions), outputs, results (or outcomes) and impacts remain an issue. While outputs can relatively easily be attributed to certain activities that are triggered (and usually also funded) through policy interventions, outcomes (e.g. the direct effects on the intended target groups) and especially impacts (e.g. the longer-term effects on the final beneficiary groups or systems not directly targeted by the intervention) are very difficult to grasp and assess.

Also the lack of widely acknowledged benchmarks in the field of Rql internationalisation makes it difficult to set targets. To give an example: Should a country, in which $15 \%$ of all professors employed in universities are coming from abroad, invest in attracting even more foreign professors or not? It is recommended to answer such a question, however, in connection with the expected outcomes attributed to the specific intervention, e.g. have the $15 \%$ increased the quality of research output or did they probably even crowd-out national human resources? There are no universal and definitely no optimum benchmarks available, because 
the context factors are varying. Thus, comparisons with other countries should be cautiously made. Relative benchmarks (e.g. by using control points over a couple of years or by comparing only with comparable countries) are thus recommended in connection with impact evaluations.

The monitoring and evaluation of international Rgl cooperation are further impeded by a lack of sufficiently good practices and standards. This starts with a shortage of guidelines as to how to formulate clear intervention logics for specific purposes (complemented by practical examples) (see section 2 of this article) in order to understand what success means so that the progress and effectiveness of international Rgl cooperation interventions can be better monitored and evaluated. Such an exercise should obviously start with the most common policy interventions in international R\&l cooperation, including collaborative activities as part of STI agreements.

Based on this, guidelines for a systematic monitoring of international RqI cooperation in order to follow up progress and enable comparison of the results over time should be developed and existing national monitoring systems accordingly adjusted.

Ideally, national R\&D surveys, which are carried out every year or every two years by the national statistics offices in each EU country, could be expanded to capture international cooperation in R\&l. The focus here should be on suggesting a limited number of meaningful indicators to assess the relevance, effectiveness and impact of $R \mathscr{C l}$ internationalisation.

The INCO MLE finally recommended that the suggested work on establishing guidelines, jointly co-created indicators and co-designed monitoring and evaluation standards as well as the testing of results-oriented indicators through a jointly launched pilot survey should be considered by SFIC (the EU's Strategic Forum for International S\&T Cooperation) and commissioned to experts, maybe with support from the European Commission.

Box 3: Monitor and evaluate international Rgl cooperation policies

The recommendation is to jointly develop monitoring and evaluation standards in order to facilitate the assessment and comparability of international $R \& 1$ cooperation activities.

The joint monitoring and evaluation standards should focus on:

- Drafting meaningful guidelines as to how to formulate a clear intervention logic and objectives for specific purposes to understand what success means.

- The development of guidelines for systematically monitoring international R\&D cooperation to follow up progress and to enable comparison of results over time

- The elaboration of a proposal for supplementing the national RGD surveys with a few meaningful indicators to assess the relevance, effectiveness and impact of R\&l internationalisation

- The preparation of a pilot survey at the European level or at least by a couple of EU Member States and Associated Countries (variable geometry) to assess the impact of national and European R\&l internationalisation activities

Addressee: SFIC or a group of European countries on the basis of variable geometry.

\section{CONCLUSIONS}

RYI internationalisation policies are facing a radical change. This applies to both the strategic direction and the operational policy-delivery. Aspects such as innovation support and international competition, consideration of the SDGs, the attempt to overcome global challenges through international cooperation, as well as tactical and ethical considerations as to who one actually wants to cooperate with and under what framework conditions are increasing significantly. This also has an impact on evaluation theory and practice. Since the focus in the past used to be on pre-competitive collaborations that were deeply rooted in basic research, it was probably sufficient to measure the scientific output and outcome of such forms of collaboration. Today's evaluations also concern questions of innovation and competition-related outputs and outcomes as well as scientific and technical contributions and their effects on solving global challenges. These are not specific challenges that only the evaluation of $\mathrm{R} g \mathrm{l}$ internationalisation interventions has to face, but general challenges for Ryl policy evaluation.

Particularly problematic, however, with regard to R\&I internationalisation policies is the extensive lack of logical impact chains as a basis for internationalisation interventions. The gap between broadly formulated overall objectives and the upstream logical elements of an intervention (outcomes, outputs, activities and inputs) is evident in many cases and system boundaries not defined. The attribution gap is exacerbated by the fact that many R\&I internationalisation measures are fragmented and subcritical, especially if they are stand-alone and are not embedded in other national Rgl interventions or at least clearly linked to them.

To make matters even more complicated, international R\&I measures are not always of a unilateral nature, but are set up bilaterally and multilaterally. This means that efforts by one country also require corresponding and coordinated efforts by the partner country or countries. Evaluations should therefore take into account the different sides of the shared intervention efforts and should therefore also be carried out in cooperation. At the level of the INCO MLE participants and their international partner countries, this hardly happened at all.

The INCO MLE has therefore rightly suggested that joint evaluation efforts to measure international R\&I cooperation, its relevance and its effects should take place under the supervision of SFIC and with the support of the European Commission. So that this does not remain a one-off matter, preliminary work would be necessary, which the interested member states would have to carry out in a coordinated action. This preliminary work concerns, for example, the definition of common indicators and the collection of suitable data on the basis of coordinated and harmonised metrics.

Such aligned efforts would increase comparability between countries, help in identifying inspiring practices and in setting target values and benchmarks. 


\section{LITERATURE}

Alkemade, F., Heimeriks, G., Schoen, A., Villard, L. and Laurens, P. (2015): Tracking the internationalization of multinational corporate inventive activity: national and sectoral characteristics. Research Policy 44(9): 1763-72.

Boekholt, P. (2019): Tools for International Cooperation: STI agreements. 2nd Thematic Report of the Mutual Learning Exercise (MLE) on National Strategies and Roadmaps for International Cooperation in R\&I. European Union. Directorate-General for Research and Innovation.

Boekholt, P., Edler, J., Cunningham, P. and Flanagan, K. (2009): Drivers of International collaboration in research. Report for the European commission, DG Research, Brussels.

Brandenburg, U. and Federkeil, G. (2007): How to measure internationality and internationalisation of higher education institutions! Indicators and key figures. CHE Arbeitspapier Nr. 83, Gütersloh: CHE Centrum für Hochschulenticklung gGmbH.

CREST Working Group (2007), Internationalisation of R\&D - facing the challenge of globalisation: approaches to a proactive International policy in S\&T, Brussles: CREST.

Dachs, B. (2017): Internationalisation of R\&D: A Review of Drivers, Impacts, and new Lines of Research. AlT. https://mpra.ub.uni-muenchen. de/83367

Deuten, J. (2015): R\&D goes global. Den Haag: Rathenau Institut.

Edler, J. and Flanagan, K. (2011): Indicator needs for the internationalisation of science policies. Research Evaluation, Volume 20, Issue 1, March 2011, Pages 7-17, https://doi.org/10.3152/095820211X12941371876148

Fikkers, D. J. and Horvat, M. (2014): Basic Principles for effective International Science, Technology and Innovation Agreements. Luxembourg: Publications Office of the European Union.

Gnamus, A. (2009): Comparative Report on S\&T Cooperation of the ERA Countries with Brazil, India and Russia. JRC Scientific and Technical Reports.

Hall, B. A. (2010), The internationalization of R\&D, Berkeley: University of California. http://elsa.berkeley.edu/users/bhhall/papers/BHH10_RND_ international_August.pdf

Hatzichronoglou, T. (2008), The Location of investment of multinationals linked to innovation, Paris: OECD.

Könnölä, T. (2019): Framework Conditions for Challenge-driven International R\&I Cooperation. 3rd Thematic Report of the Mutual Learning Exercise (MLE) on National Strategies and Roadmaps for International Cooperation in R\&l. European Union. Directorate-General for Research and Innovation.
Laurens, P., C. Le Bas, A. Schoen, L. Villard, and P. Larédo. (2015): 'The rate and motives of the internationalisation of large firm R\&D (19942005): Towards a turning point? ' Research Policy 44(3): 765-76.

Meyer-Krahmer, F., Grech, J., Sánchez, B., Wilson, D. and Zagar, P. (2019): Final Report of the Horizon 2020 Commission Expert Group for the evaluation of the Horizon 2020 Policy Support Facility. European Union. doi: $10.2777 / 433930$

OECD (2016): Attracting international S\&T investments by firms, in: OECD (Ed.), OECD Science, Technology and Innovation Outlook 2016. OECD, Paris.

OECD (2010): Measuring Globalisation: OECD Economic Globalisation Indicators 2010, Paris: OECD.

OECD (2008a): The Internationalisation of business R\&D: evidence, impacts and implications, Paris: OECD.

OECD (2008b): Open Innovation in Global Networks, Paris: OECD.

OECD (2008c): Recent trends in the internationalisation of RGD in the enterprise sector, Paris: DSTI/EAS/IND/SWP (2006)1/Final.

OECD (2005): Measuring globalisation: OECD economic globalisation indicators, Paris: OECD.

Schuch, K., Gustafsson, G., Boekholt, P. and Könnölä, T. (2020): International R\&I Cooperation policies revisited: sustained challenges and new developments. Final Report of the Mutual Learning Exercise on National Strategies and Roadmaps for International Cooperation in R\&l. European Union. Doi: 10.27777/368726

Schuch, K. (2019): Design and Development of National Strategies. 1st Thematic Report of the Mutual Learning Exercise (MLE) on National Strategies and Roadmaps for International Cooperation in R\&l. European Union. Directorate-General for Research and Innovation.

Schuch, K. (2011): Indikatoren zur Messung der Internationalisierung von Wissenschaft und Forschung. Im Auftrag des BMWF. Wien: Zentrum für Soziale Innovation.

Schwaag Serger, S. and Remoe, S. (eds.) (2012): Report of the Expert Group established to support the further development of an EU international STI cooperation strategy. Luxembourg: Publications Office of the European Union, 2012.

Schwaag Serger, S. and E. Wise (2010), Internationalization of Research and Innovation - new policy developments, Seville: paper presented at the 2010 Concord Conference.

SFIC (2019): Final report of the SFIC Benchmarking Working Group on the Benchmarking exercise on strategies and roadmaps for international cooperation in Ryl. EUROPEAN RESEARCH AREA AND INNOVATION COMMITTEE Strategic Forum for International S\&T Cooperation. ERACSFIC 1359/19. December 2019. 
SFIC (2018): Overview of Tools for International Research Cooperation in Science and Technology Matters. EUROPEAN RESEARCH AREA AND INNOVATION COMMITTEE Strategic Forum for International S\&T Cooperation. ERAC-SFIC 1358/18. December 2018.

SFIC (2015): SFIC opinion on Common principles for the conduct of international R\&I cooperation. EUROPEAN RESEARCH AREA AND INNOVATION COMMITTEE Strategic Forum for International S\&T Cooperation. ERAC-SFIC 1357/15; 18. Juni 2015.

TAFTIE (2009), Internationalisation of National Innovation Agencies, Stockholm: TAFTIE.

Shapira, P., J. Edler, D. Gagliardi, A. Verbeek, E. Lykogianni, and M. Knell (2009), Analysis of R\&D international funding flows and their impact on the research system in selected Member States, Brussels: RINDICATE specific assignment 7.

UNCTAD (2005), World Investment Report 2005: Transnational Corporations and the Internationalization of R\&D, New York and Geneva: United Nations.

Vullings, W., Boekholt, P., van Til, J., Steinz, H., Cunningham, P., and Flanagan, K. (2013): Overview of international science, technology and innovation cooperation between Member States and countries outside the EU and the development of a future monitoring mechanism. Luxembourg: Publications Office of the European Union.

\section{AUTHOR}

\section{KLAUS SCHUCH}

ZSI - Centre for Social Innovation, Austria

Linke Wienzeile 246, 1150 Vienna

E: schuch@zsi.at

ORCID: 0000-0002-7603-4384

Acknowledgements

The author sincerely acknowledges the feedback from the two peer reviewers.

The author acknowledges the support provided by the European Commission to this Mutual Learning Exercise and especially the intellectual contributions of all delegates from the participating countries and in particular, of my expert colleagues, Gunnel Gustafsson, who was the chair of the Mutual Learning Exercise, Patries Boekholt and Totti Könnölä. The findings of this Mutual Learning Exercise, which are presented in this article, are published in Schuch, K., Gustaffson, G., Boeholt, P. and Könnölä, T. (2020).

\section{KEYWORDS}

Internationalisation; techno-globalisation; European Ryl internationalisation; INCO, international cooperation in science, research and innovation 